\title{
BARGAINING EFFICIENCY AND SCREENING: AN EXPERIMENTAL INVESTIGATION
}

\author{
Gary Charness \\ Department of Business and Economics \\ Universitat Pompeu Fabra \\ Barcelona, Spain 08005 \\ e-mail: charness@upf.es
}

January, 1998

Keywords: Bargaining efficiency, Dispute resolution, Experiment, Fairness, Sorting JEL Classifications: J52, C91, C78

${ }^{1 *}$ I wish to thank the Russell Sage Foundation, the Economic Science Laboratory, and GTE Mini-Grants for funding. Matthew Rabin, Rachel Croson, and Matthew Speigel provided valuable comments and suggestions. I thank Vernon Smith and the ESL for the use their experimental facilities. Li Gan and Clara Wang provided econometric help. All errors are my own. 


\begin{abstract}
This paper investigates whether information about fairness types can be useful in lowering dispute costs and enhancing bargaining efficiency. An experiment was conducted in which subjects were first screened using a dictator game, with the allocations chosen used to separate participants into two types. Mutually anonymous pairs of subjects then bargained, with a dispute cost structure imposed. Sorting with identification reduces dispute costs; there are also significant differences in bargaining efficiency across pairing types. Information about types is crucial for these differences and also strongly affects the relative bargaining success of the two types and the hypothetical optimal bargaining strategy.
\end{abstract}




\section{INTRODUCTION}

Disputes and bargaining inefficiency can result in substantial economic costs. In some cases, these costs may be unnecessarily high. This paper presents experimental evidence that a pair's bargaining behavior can be affected by sorting people into "fairness" types and providing each participant with information about the type of person with whom $\mathrm{s} / \mathrm{he}$ is paired. In some cases, this can induce a less partisan negotiation process. While circumstances may sometimes require adversarial behavior, at other times this may be largely a consequence of beliefs that one must be adversarial to avoid exploitation. The results indicate that sorting with information is effective in increasing bargaining efficiency, but that sorting alone is insufficient for this purpose.

Roth and Malouf (1979) and Roth and Schoumaker (1983) have demonstrated the importance of information and expectations in bargaining. Such information need not be limited to payoffs and reservation values. Behavior during bargaining or disputes may also reflect considerations of non-pecuniary utility. While many traditional economic models assume that people pursue only their pecuniary self-interest, considerable experimental research indicates otherwise. Examples include the positive provision of public goods and

behavior in ultimatum and dictator games. ${ }^{2}$ Rabin (1993) provides a game-theoretic model of fairness which

\footnotetext{
${ }^{2}$ In the simple ultimatum game, a sum of money is provisionally allocated to a pair. One member of the pair is randomly selected to propose a division of this sum. The other member can accept or reject this proposal. Players receive the proposed sums when a proposal is accepted and both receive zero when a proposal is rejected. Results show that people will reject positive sums of money if a proposed allocation is felt to be inappropriate.
}

In a dictator game, one person in a mutually anonymous pair unilaterally chooses a division of a sum of money between the two members of the pair. There have been numerous studies utilizing dictator games as a tool for examining implicit social norms in bargaining behavior. Pecuniary self-interest predicts that allocators should take the entire sum. Yet, this is quite often not the case. See Roth (1995) and Guth and Tietz (1990) for surveys of this literature 
incorporates non-pecuniary concerns. This model relies on the notion that one's behavior may well be affected by both how another has acted and

one's beliefs about the underlying motivations for this action. While historical actions are not considered by Rabin, one might expect

information about past "fairness" behavior to alter expectations and thus beliefs and choices of actions in bargaining. For example, an individual

may negotiate more cooperatively with another person who has been identified as having similar social norms or beliefs. 3 Absent this

information, one might wish to be cooperative, but be concerned that any such attempts at cooperation would signal weakness. However, this

information could enable bargainers to ignore the strategic imperatives which could ordinarily dictate aggressive or highly partisan behavior.

Each experiment had two stages. The first stage of this experiment consisted of a

dictator game. In the second stage, subjects were sorted, on the basis of their offers in this exercise, into two groups and paired for a bargaining session, wherein a dispute cost structure was imposed. ${ }^{4}$ Each person was classed as either a "high" (H) type or "low" (L) type based on the allocations chosen. Different treatments were conducted, in order to separate pure pairing effects from informational effects. In the first, subjects selected their dictator game allocations without the knowledge that their choices would then be used for sorting purposes. Prior to the bargaining session, each subject was informed of his type and the type of his counterpart, as well as the definition of "types." In the second treatment, the subjects are prescreened and sorted as before. However, in this case subjects are not given any information about types. Finally, in the third treatment subjects are informed prior to the dictator game that there will be sorting, with like-type pairings. 5

In Treatment 1, the experimental results show that there are significant differences in the cost of disputes across pairing types, with the lowest bargaining inefficiency found in pairings of two high types. Identification and sorting into like-types significantly lowers dispute costs. $\mathrm{H}$ types also have higher net earnings in the bargaining game than do $\mathrm{L}$ types. The evidence suggests that mixed pairs have the most difficulty in reaching

\footnotetext{
3 This can happen informally in real disputes: If you have a dispute with someone, the natural tendency is to view this person as unreasonable. However, if you have a close friend who knows the other person well and who vouches for their character, your bargaining/disputing behavior and attitude may very well be altered. In this way, identification and sorting might facilitate cooperation where the parties would otherwise focus on their differences.

4 Payoffs in the bargaining experiment were reduced by $4 \%$ after each 100 seconds of non-settlement. In addition, an arbitration cost of $20 \%$ was imposed if no settlement was achieved in the allotted time of 600 seconds. See section 4 for further details.
} 
settlements. However, Treatment 2 indicates that these differences practically disappear without the provision of information about types. Here L types have higher net earnings than $\mathrm{H}$ types and $\mathrm{L}$ types are much more successful than $\mathrm{H}$ types in mixed pairs. Treatment 3 suggests that the differences found in the 1st study will persist when a screening mechanism is anticipated, although these differences are diminished. In addition, dictator allocations were significantly higher, indicating that subjects valued being in the $\mathrm{H}$ group.

The freedom to negotiate more cooperatively can generate benefits for those who choose this path. If it is true that $\mathrm{H}$ types are merely "weak" players, we would expect $\mathrm{L}$ types to achieve higher earnings. Yet, on average, $\mathrm{H}$ types earn more than $\mathrm{L}$ types in Treatment 1, as pairings of two $\mathrm{H}$ types have far lower dispute costs. This effect is seen to be due to the information about types, since the earnings differential is reversed in Treatment 2, whereas $\mathrm{L}$ types earn more than $\mathrm{H}$ types absent the disclosure of types. Simulated optimal strategies, which assume that one could mimic either type's bargaining behavior, indicate that a strategic player would prefer to act as an $\mathrm{H}$ type in Treatment 1 if the fraction of $\mathrm{H}$ types in the population is more than $26 \%$. However, in the 2 nd treatment, it is best to follow the "strategic imperative" of non-cooperation and act as an L type, regardless of the population's composition.

Thus, it is found that not only does sorting with identification result in greater bargaining efficiency, it also changes optimal behavior, theoretical equilibrium outcomes and type distributions in equilibrium. Fairness and non-pecuniary concerns can be important in bargaining and disputes.

\footnotetext{
5 This treatment perhaps better approximates the situation in the field, where any screening mechanisms would likely be apparent.

${ }^{6}$ Some empirical support for this view is provided by the success of the tit-for-tat strategy in repeated prisoner dilemma tournaments (Axelrod and Hamilton, 1981 and Axelrod, 1984) and evolutionary models (Frank, 1988).
} 


\title{
2. THEORY AND PREDICTIONS
}

\section{Theory}

\author{
The information provided by sorting may influence expectations and even \\ bargainer preferences. Harsanyi and Selten (1988) point out that if expectations are to \\ some degree exogenous, we might see outcomes which would not otherwise be predicted. \\ In general, bargaining under uncertainty will fail to be Pareto-efficient, as shown by Chatterjee and Samuelson (1983) and Fudenberg and Tirole \\ (1983). However, additional information can serve to reduce this inefficiency, perhaps by reducing the degree of uncertainty. Here we have an \\ incomplete-information game with heterogeneous bargaining behavior. If types have differing exogenous expectations, the likelihood of
} disagreement might well be increased.

\section{A number of experimental works explore expectations and information in} bargaining environments. Roth and Malouf (1979) and Roth and Schoumaker (1983) explore the effects of exogenous expectations on bargaining. ${ }^{8}$ The earlier study varies information conditions across treatments in a pie-splitting game, creating different exogenous expectations and very different outcomes in the various treatments. The latter study manipulates such expectations in a series of experiments; the results suggest that common expectations allow individuals to efficiently reach agreement and that it may be necessary to incorporate the expectations of the bargainers into any description of equilibrium outcomes. Cooper et al (1992) find that the extent to which expectations are shared can also determine whether Pareto-superior or Pareto-inferior outcomes are realized in a bilateral coordination game. ${ }^{9}$ From the social psychology literature, Kelley and Stahelski (1970), while offering evidence that cooperators are often reciprocal altruists, find non-mutual exogenous expectations across types. Dawes et al (1977) find that exogenous expectations can be affected by information provided in the game environment, as behavior in the prisoner's dilemma is seen to greatly affected by "relevant" communication between players.

\footnotetext{
${ }^{7}$ Endogenous expectations are based solely on factors internal to the game, whereas exogenous expectations may include beliefs or notions not strictly internal. While standard theory insists on common expectations in equilibrium, most bargaining or disputant behavior is non-repeated, so that heterogeneous expectations are likely.

${ }^{8}$ See also Croson (1993) for information effects in experimental games.
} 
Sorting with identification can affect bargaining behavior via both strategic and non-strategic channels. Albin (1993) argues that concepts of fairness can be an influential factor in negotiations, impacting the positions and expectations which the parties bring to the bargaining table. Perhaps one weights another person's welfare differently with sorting. Rabin (1993) demonstrates that considerations of fairness can affect choices and outcomes:

$$
\mathrm{U}_{\mathrm{i}}\left(\mathrm{a}_{\mathrm{i}}, \mathrm{a}_{\mathrm{j}}, \mathrm{r}_{\mathrm{i}}\right)=\Pi_{\mathrm{i}}\left(\mathrm{a}_{\mathrm{i}}, \mathrm{a}_{\mathrm{j}}\right)+\mathrm{r}_{\mathrm{i}} * \mathrm{f}_{\mathrm{i}}\left(\mathrm{a}_{\mathrm{i}}, \mathrm{a}_{\mathrm{j}}\right)
$$

Here $\mathrm{Ui}$ is the utility function for player $i, \Pi_{i}$ is the monetary payoff to player $i$, and the final term represents psychological utility. $f_{i}\left(a_{i}, a_{j}\right)$ is the kindness function, and $r_{i}$ is player $i^{\prime}$ ' "disposition" towards player $\mathrm{j}$; both $\mathrm{f}_{\mathrm{i}}$ and $\mathrm{r}_{\mathrm{i}}$ can be either positive or negative. ${ }^{10}$ His model relies on the notion of reciprocity. A player who is favorably (unfavorably) disposed toward another would be willing to sacrifice money to make the other better (worse) off. In the sorting context, when one is able to identify another as a certain type, one's disposition towards the other may be affected. This, in turn, would affect the underlying utility function and choices of actions. Note that when subjects with mutually positive dispositions are paired, Rabin would predict earlier settlements.

This model also provides strategic incentives for a bargainer to take into account the results of sorting. Even if pecuniary reward is the only concern, one must weigh any presumed advantages of being a tough bargainer against the risk of inducing a strongly negative disposition in one's counterpart. A hostile attitude could lead to costly delays and

\footnotetext{
${ }^{9}$ In their study, "egotists" are generally not able to achieve the Pareto-superior outcome, even when it is common knowledge that the proportion of "altruists" is high.

10 The original 1993 paper defines the utility function as:

$$
\mathrm{U}_{\mathrm{i}}\left(\mathrm{a}_{\mathrm{i}}, \mathrm{a}_{\mathrm{j}}, \mathrm{c}_{\mathrm{i}}\right)=\Pi_{\mathrm{i}}\left(\mathrm{a}_{\mathrm{i}}, \mathrm{a}_{\mathrm{j}}\right)+\mathrm{f} \sim \sim_{\mathrm{j}}\left(\mathrm{a}_{\mathrm{j}}, \mathrm{c}_{\mathrm{i}}\right) *\left[1+\mathrm{f}_{\mathrm{i}}\left(\mathrm{a}_{\mathrm{i}}, \mathrm{a}_{\mathrm{j}}\right)\right]
$$

where $c_{i}$ represents player i's beliefs about what player $j$ believes player i's strategy is. Rabin notes that $f \sim_{j}\left(a_{j}, c_{i}\right)$ is formally equivalent to $f_{j}\left(a_{j}, a_{i}\right)$. Later versions use the formulation given in the text, where a negative $r_{i}$ means that a player would choose a negative $f_{i}$ to maximize one's utility, while a positive $r_{i}$ leads to a choice of a positive $f_{i}$.
} 
even a failure to reach a settlement. A cooperative approach is advantageous if dispositions are highly volatile.

\section{Predictions}

If subjects are purely strategic and pre-sorting with identification provides no useful information, then we would expect no significant differences in dispute costs for the various pairings and also no differences in earnings for $\mathrm{H}$ and $\mathrm{L}$ types. If we believe that the information provided changes expectations, the Roth model predicts more difficulty in reaching agreement for two subjects with non-matching expectations (CROSS pairs). This theory makes no clear statement about relative earnings for $\mathrm{H}$ and $\mathrm{L}$ subjects and does not anticipate any difference in dispute costs between $\mathrm{HH}$ pairs and LL pairs. The Rabin model also offers little guidance about relative earnings. On the other hand, the Rabin model predicts $\mathrm{HH}$ pairs will have lower dispute costs than LL pairs, if it is assumed that the non-pecuniary portion of the utility function is more significant for $\mathrm{H}$ types. ${ }^{11}$ The prediction for mixed pairs is less clear. If $\mathrm{H}$ types are predominantly pure altruists, mixed pairs should have lower dispute costs. On the other hand, if $\mathrm{H}$ types are reciprocal altruists and have a negative disposition toward the $\mathrm{L}$ type person in the pair, this would hinder settlement.12 A negative disposition, possible if one member of a pair is unhappy with the other, would hinder settlement, while the opposite is true for positive dispositions. Thus, a comparison of dispute costs for mixed pairs and low pairs offers some evidence on the prevalence of reciprocal altruists in the $\mathrm{H}$ population.

\footnotetext{
${ }^{11}$ I am not suggesting that $\mathrm{L}$ types universally have $\mathrm{r} * \mathrm{f}=0$. However, it seems reasonable to assume that fairness is less important to $\mathrm{L}$ types than to $\mathrm{H}$ types, so that the absolute value of $\mathrm{f}$ would be lower for the latter. Assuming that paired high-types maintain mutually positive dispositions, the results still hold. 12 A pure altruist always wishes to help another, so has a largely unvarying positive disposition. A reciprocal altruist's disposition toward another depends on circumstances and beliefs and can range from highly positive to strongly negative.
} 


\section{EXPERIMENTAL DESIGN}

The dictator game design used in Forsythe, Horowitz, Savin, and Sefton (1994) and the bargaining experiment of Ashenfelter, Currie, Farber, and Spiegel (1992) were adapted for this experiment. Dictator game results are historically very sensitive to the precise phrasing of the instructions, as the social norms in this situation are ill-defined..$^{13}$ The results in the Forsythe et al (1994) experiment were characterized by a relatively even spread of allocations. In their treatment, exactly half of the allocations to the "recipient" were $30 \%$ or greater. My version used a $\$ 5$ dictator game, where all subjects made allocations. 14 The proposal

form is shown in Appendix B. As previous data suggested that half of the offers would be less than $\$ 1.50$ and half would be $\$ 1.50$ or more, each subject was classed as a "high" type if they allocated $\$ 1.50$ or more to the recipient and as a "low" type otherwise.15 The instructions for this experiment are presented in Appendix A.

This Ashenfelter et al (1992) bargaining experiment introduced arbitration as a background feature to the bargaining game. The arbitrator's behavior was controlled by having the "arbitrator's decision" be simply a draw from a truncated normal distribution. Subjects were first given a list of previous arbitrator decisions and were specifically informed that this decision is independent of their bargaining behavior. Subjects bargained over a number between 100 and 500 and could only communicate by making or accepting offers. Players' payoffs were symmetric, but opposed. ${ }^{16}$

\footnotetext{
${ }^{13}$ Hoffman et al (1994) provides a good illustration of this.

14 Subjects were assured that real people (not in the room) would receive whatever was specified and that their allocations were anonymous. This was indeed the case - subjects in one session were randomly matched with subjects in the next session, who received the allocated amounts. Subjects in the 1st session received the amounts contributed by the subjects in the final session.

15 The application of this rule here resulted in $56 \%$ of the subjects being classified as L types in Treatment 1 and $51 \%$ being classified as L types in Treatment 2 .

16 By this I mean that the payoffs for one subject in each pair grew as the settlement number increased, while the reverse was true for the other subject in the pairing. Subjects were generally aware that if their payoffs increased (or decreased) with increasing settlement numbers, the reverse was true for their counterpart's payoffs. However, no indication was given that these payoffs were symmetric.
} 
My experiments took place at the University of Arizona. Undergraduate students, primarily economics majors, were recruited by telephone calls and by visiting undergraduate classes. Each session lasted about 1.5 hours and average earnings were about $\$ 13$, including the $\$ 5$ show-up fee. Subjects were seated in carrels with panels, preventing subjects from seeing other computer terminals and earnings were paid privately. The bargaining range was from 100 to 500, with the mean of the arbitrator distribution set at 300. ${ }^{17}$ A list of the past 100 arbitrator decisions was given to the participants and is shown in Appendix E. There was a practice round to familiarize the subjects with mechanics and to minimize confusion and errors. If no voluntary settlement was reached in 600 seconds, a settlement was imposed through arbitration. 18 There were generally two rounds at each session; each subject was re-paired with a new person and was specifically informed that this was someone with whom s/he had never previously been paired. There was no real pattern to the re-pairings and a test for order effects using the Wilcoxon signed-ranks test (see Siegel, 1992) showed no significant bias.

One innovation involved measuring the cost of non-agreement, rather than dispute rates per se. From an economic standpoint, settlement rates only seem important when there is a cost to non-settlement. In practice, arbitration does involve some cost, both direct and indirect. The cost structure consisted of a "time decay" cost and a cost of arbitration. ${ }^{19}$ The decay cost was an attempt to simulate bargaining rounds in a single dispute, with a small cost for each round. If the matter was referred to arbitration, an additional arbitration cost of $20 \%$ was imposed. Subjects were given a sheet of supplemental instructions which explained the costs of non-settlement over time. A copy of these supplemental instructions is presented in Appendix C. The dispute cost, defined as the percent shrinkage from the maximum potential total payoff, is illustrated in Figure 1:

\footnotetext{
17 In contrast, the mean of the arbitrator distribution was 350 in Ashenfelter et al. However, a biased mean could be a confounding factor, potentially stimulating a higher percentage of disputes. Bolton (1995) tests this hypothesis, finding that award asymmetry does in fact causes higher dispute rates.

18 This bargaining period, which was only 330 seconds in Ashenfelter et al (1992), was extended to attempt to ensure that subjects had plenty of time to reach an agreement and that any non-settlement was intentional, not accidental.

${ }^{19}$ For the time decay, the payoffs shrank by $4 \%$ after 100 seconds had elapsed and by an additional $4 \%$ each time an additional 100 seconds passed without an accepted offer. However, if no agreement was reached during the final 100 seconds, the dispute went to arbitration, with payoffs reduced by a final $20 \%$ (instead of $4 \%$ )
} 


\section{Figure 1}

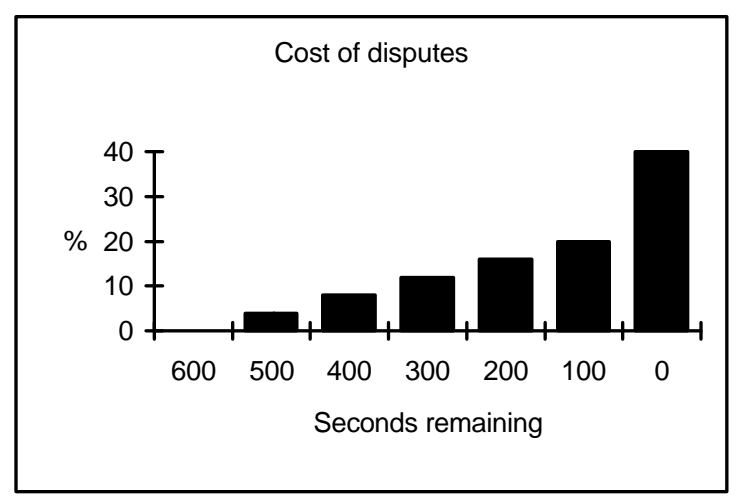

\section{RESULTS}

In all treatments, the non-parametric Wilcoxon-Mann-Whitney and Epps-Singleton tests were used to check for significant differences in dispute costs and earnings. Regressions on cost and earnings, using dummy variables, were also performed and offer similar results. However, the distributional assumptions implicit with regressions may not be warranted here, so the regression results are not reported. ${ }^{20}$ A summary of the data for all treatments is presented in Appendix F.

Treatment 1. In this study, subjects knew their type and the type of their counterpart before the bargaining session. After the dictator game, it was explained that subjects had

\footnotetext{
${ }^{20}$ Non-parametric tests make very few assumptions about the population and its distribution (see Siegel, 1992). The conclusions drawn from non-parametric tests require fewer qualifications and are therefore stronger than conclusions reached using parametric tests. However, it may be correspondingly more difficult to find statistical significance for results.
} 
been sorted and the sorting rule was described. Each individual was then given a slip of paper indicating their type ( $\mathrm{H}$ or $\mathrm{L})$ and the type of the other member of the pair. At this point, the second stage of this experiment was conducted. There were a total of 124 bargaining sessions conducted. Of these, 28 were HH pairs, 40 were LL pairs, 26 were cross-pairs, and 30 were unsorted pairs. The average cost of disputes is shown in Table 1 below.

\section{Table 1}

$\underline{\text { PAIRING-TYPE }}$

$\mathrm{HH}$

LL

CROSS

UNSORTED

\section{$\underline{\text { AVG. DISPUTE COST }}$}

$12.8 \%(2.3)$

$16.1 \%(3.0)$

$12.8 \%(2.3)$

Numbers in parentheses are standard errors of the averages.

A glance at the table shows that there are some significant differences across types. The cost of disputes for $\mathrm{HH}$ pairs is dramatically lower than for any other category. The Wilcoxon and Epps-Singleton tests easily reject the null hypotheses that the cost of disputes is higher for $\mathrm{HH}$ pairs than for the unsorted control group, LL pairs, or mixed pairs at the $1 \%$ level. The data also indicate that sorting with identification significantly enhances bargaining efficiency, as the null hypothesis that the cost of disputes for like- 
sorted pairs is more than that for unsorted pairs is rejected at the $2 \%$ level by the Wilcoxon test and the $1 \%$ level by Epps-Singleton. ${ }^{21}$

While dispute costs for mixed pairs are the highest of all categories, the difference between LL pairs and mixed pairs is not significant at conventional levels. The EppsSingleton and Wilcoxon tests give p-values of .17 and .13, respectively, for the rejection of the hypothesis that costs are higher for LL types. Overall, the data does suggest that cross-pairing adversely affects dispute costs and earnings, but is not conclusive. There is also some evidence that suggests that low types bargain more aggressively in cross-pairs than in LL pairs, supporting the view that L-types attempt to exploit the presumed weakness of H-types. ${ }^{22}$

On average, $\mathrm{H}$ types do indeed have higher net earnings than L types, by a margin of 330.5 to 311 . A one-tailed Wilcoxon test on net earnings finds this difference significant at a p-value of .06 . This result is largely driven by the difference in dispute costs between HH and LL groups. Nonetheless, the evidence does suggest that high types are not simply compliant players; even when we examine earnings only in cross-pairings, we see no real difference in earnings across types. If $\mathrm{H}$ types were simply pure altruists, we might expect them to have significantly lower earnings than the L types in the crosspairs. However, this is not the case, as the cross-pair earnings for the two types are nearly identical. Results for the 26 cross-pairings are shown in Appendix G.

\footnotetext{
${ }^{21}$ Only like-sorted pairs are included in these statistical tests, as the purpose of sorting would be to pair similar types with one another.

22 The mean first offer made by a low-type in a cross-pair was 48.8 from the extreme in the range (from 100 to 500), whereas this mean for first offers in LL pairs was 67.2 .
} 
Treatment 2. While Treatment 1 finds significant differences across pairing-types, it does not indicate whether these differences are the result of "innate" differences in bargaining styles or whether the provision of information about types is critical. In the second treatment, the subjects are pre-screened as before, but are not given any information about types. The experimental procedure for Treatment 2 was otherwise identical to that for Treatment 1. If we still observe major differences in costs across pairing-types, then we should conclude that this information is not critical. On the other hand, if differences in dispute cost disappear without this information, then there is more scope for a mechanism to diminish dispute costs by providing evidence of a like-type pairing where one exists. The average cost of disputes for each pairing-type is shown in Table 2.

\section{Table 2}

$\underline{\text { PAIRING-TYPE }}$

$\mathrm{HH}$

LL CROSS $\underline{\text { AVG. DISPUTE COST }}$

$9.2 \%(1.6)$

$9.4 \%(2.1)$

$11.8 \%(2.6)$

Numbers in parentheses are standard errors of the averages.

The cost of disputes is nearly identical for $\mathrm{HH}$ and LL pairings. Absent information about types, any difference in cost between HH and LL pairs seems to vanish. The Wilcoxon test shows no significant difference between HH and LL pairs. There is a moderate difference between dispute costs for like-pairs and cross-pairs. However, while 
there may be slightly lower bargaining inefficiency for cross-pairs here, the difference is relatively small and inconclusive.

A major change from the Treatment 1 results is that here $\mathrm{L}$ types had higher average earnings than did $\mathrm{H}$ types. An analysis of the data for earnings for $\mathrm{H}$ and $\mathrm{L}$ types in the 33 cross-pairs is presented in Appendix $\mathrm{H}$ and is revealing. Previously, we observed that the earnings for $\mathrm{H}$ and $\mathrm{L}$ types in cross-pairs were virtually identical. However, when the subjects are uninformed, the L type does better (in voluntary settlements) than the H type in 18 times and the $\mathrm{H}$ type does better 6 times. $^{23}$ The Wilcoxon, Epps-Singleton, and binomial tests all find this significant at the $1 \%$ level. It seems that $\mathrm{H}$ types can be "exploited" when not forewarned of the type of their counterpart. In the Treatment 2 population at large, the earnings disparity found in Treatment 1 remains about the same size, but the direction is reversed - L types earn 334.5, while H types earn only 311 . The one-tailed Wilcoxon test on net earnings again finds this difference significant at a p-value of .06.

Treatment 3. In the field, bargainers might be aware of a screening mechanism being used. One practical consideration is whether differences in dispute costs survive possible "pooling" behavior in the form of higher (or lower) dictator game allocations, chosen from strategic considerations? If we still observe differences in dispute costs, there is greater scope for employing a sorting and identification mechanism as a policy intervention.

The experimental design was again quite similar to that in Treatment 1, except that here subjects were told that their dictator game allocations would determine their group in the bargaining phase. Subjects whose chosen dictator allocations were in the higher (lower) $50 \%$ of the population were to be placed in the high (low) group. People would only be paired with others in the same group. There were 64 subjects and 68 bargaining 
sessions in Treatment. ${ }^{24}$ A copy of the modified dictator game instructions is presented in Appendix D. Prior to the dictator game subjects played a practice round to familiarize themselves with the bargaining game.

The average cost of disputes for each pairing-type is shown in Table 3.

\section{Table 3}

\section{PAIRING-TYPE}

$\mathrm{HH}$

LL
AVG. DISPUTE COST

$8.7 \%(1.4)$

$12.9 \%(2.2)$

Numbers in parentheses are standard errors of the averages.

Although the LL average cost is almost 50\% higher than the $\mathrm{HH}$ average cost, non-parametric tests give mixed results. While the Wilcoxon test only rejects the alternative hypothesis that $\mathrm{C}(\mathrm{HH})>\mathrm{C}(\mathrm{LL})$ at a $\mathrm{p}$-value of .15 , a test of proportions on the relative number of non-voluntary settlements is significant at a $4 \%$ level. The $\mathrm{HH}$ pairs have a lower average dispute cost; since there are no mixed pairs, $\mathrm{H}$ types must have higher earnings. However, the difference, 328.7 vs. 313.6 , is only significant at $\mathrm{p}=.15$. Perhaps statistical significance would be attained with a larger data sample. It seems reasonable to observe that there seem to be differences which survive the revealed screening mechanism, although these differences have been somewhat diminished by the revelation.

\footnotetext{
${ }^{23}$ There were 33 mixed pairs, but 6 sessions were arbitrated and 3 others were evenly split.

${ }^{24}$ There were precisely 8 participants in each session, ensuring even match-ups. Participants expected to play 2 rounds; in one case, subjects played an extra round. There was a new pairing each time.
} 
The dictator game allocations made in this treatment were substantially different than in the others. As Treatments 2 and 3 were run contemporaneously, these results are compared. The mean allocation to another was $\$ 1.27$ in Treatment 2 and $\$ 1.78$ in Treatment 3. The Wilcoxon test finds this difference significant at a p-value of .02 . Subjects valued being in the high group and were willing to "bid" an average of $\$ .50$ more to attempt to qualify for it.

Finally, an unintended test of gender effects occurred in Treatment 3. As it happened, one session was attended of 8 females, while another session was comprised of 8 males. In both cases, the participants were aware that gender was homogenous for their group. The average dispute cost was $6.7 \%$ for the female group, but was $16.0 \%$ for the male group. The Wilcoxon test suggests significance at a p-value of .01. The data is presented in Appendix I.

\section{DISCUSSION}

The three experimental studies provide evidence that information about historical anonymous generosity affects negotiation behavior and results. Sorting with identification improves bargaining efficiency. The information about types is essential for the results observed in Treatment 1, as it affects the positions and expectations which the parties bring to the bargaining session. These results support the findings in Roth and Malouf (1979) and Roth and Schoumaker (1983). Exogenous expectations, based on information about chosen dictator game allocations, have serious effects on outcomes. As in Dawes (1977), player's beliefs and assumptions about others, which is influenced by relevant 
communication, do affect behavior. Roth (1985) and Cooper et al (1992) stress coordination problems inherent in the bargaining process; the latter study indicates that the extent to which expectations are shared can determine the outcome in a coordination game. Here, we also see that information about historical generosity can lead subjects to believe that norms are shared, alleviating coordination problems and allowing a more efficient resolution.

Subjects either have non-pecuniary concerns or at least believe that other subjects do. If we allow past actions to affect current dispositions, the Rabin fairness model can be applied to explain differences in dispute costs across pairing-types. Mutually positive dispositions will lead to more cooperative bargaining behavior and an expanded settlement range, whereas negative dispositions can cause disputants to sacrifice some material payoff to punish others, thereby exacerbating the difficulties in reaching a settlement. In line with this model, the data provides some evidence of reciprocal altruism in the population. Negotiations are facilitated between "cooperative" people when they are given evidence that both parties are at least potentially cooperative, while dispositions may be negative in mixed pairs, adversely impacting settlement.

Treatment 1. The low dispute cost for $\mathrm{HH}$ pairs is the most notable observation. In these pairs, there seems to be little need for extended negotiations and arbitration is rarely required. The gain in bargaining efficiency from $\mathrm{HH}$ pairs is primarily the driving force behind the benefits from pairing similar types, although there is also some evidence that LL pairs negotiate together more effectively than do mixed pairs. If we believe that better information facilitates bargaining, it should not be surprising that sorting and identification 
enhances bargaining efficiency. The subjects appear to believe that they can extract meaning from the knowledge of another person's type. Like-sorting may more generally serve to align perceptions of fairness or expectations of fair treatment. ${ }^{25}$ Where it is possible to identify disputants as the same type, a mechanism of screening and identification offers some potential for reducing dispute costs.

The net earnings differential in favor of $\mathrm{H}$ types indicates that those who are less generous do not necessarily bargain more successfully, particularly when costs are taken into account. Direct evidence from the cross-pairings shows that when they are forewarned about being paired with $\mathrm{L}$ types, $\mathrm{H}$ types achieve even settlements, on average. If higher earnings are a "survival trait", this is in keeping with the scrutiny results in Frank (1988). Finally, the evidence from the dispute costs for cross-pairs supports the view that there are many reciprocal altruists in the population. If $\mathrm{H}$ types were predominantly pure altruists, impasses should be less frequent for cross-pairs than for LL pairs. Yet cross-pairs had the highest mean cost of dispute and the highest rate of nonsettlement, even though the difference in cost is not significant at conventional levels. Divergent views of fairness may lead to more frequent impasses.

Treatment 2. Here we see that it is necessary to provide participants with information about individual types, as the differences in bargaining behavior observed in the first treatment largely vanish absent information about types. The difference is most striking for $\mathrm{HH}$ pairs, as the data again strongly suggest that it is these who particularly benefit from the information about the participants' types. While mixed pairs have slightly higher

\footnotetext{
25 There is some evidence that suggests that low types bargain more aggressively in cross-pairs than in LL pairs, supporting the view that L-types attempt to exploit a presumed weakness in H-types. The mean first offer made by a low-type in a cross-pair was 148.8, whereas this mean for first offers in LL pairs was 167.2, adjusting the figures so that the L-type always prefers low numbers. The range was 100 to 500 .
} 
dispute costs, this modest difference means that pairing similar types is not per se enough to effectively reduce dispute costs. As it must be the information that leads to the differences seen in Treatment 1, this is consistent with the results of Roth and Schoumaker (1983) and support the theoretical views of Roth (1985).

$\mathrm{L}$ types earn more than $\mathrm{H}$ types when types are not known by the bargainers and the cross-pair results are strikingly in favor of the hidden L types. Apparently those people who are less generous (or less concerned with another's welfare) can generally be more successful in bargaining when other people are not informed of their "type." This result is more in line with the folk wisdom that "nice guys finish last." However, Treatment 1 shows this isn't true for an informed nice guy. The provision of information about types changes the optimal strategy, discussed below.

Treatment 3. This study investigates whether differences in dispute costs survive awareness that a sorting process is being employed. Although the higher dictator allocations made in this treatment are evidence of some pooling behavior and a diminished credibility that "types" were accurate, we see that there is still nearly difference between the cost of disputes for $\mathrm{HH}$ and LL pairs. This implies that a real screening and identification mechanism could be effective in reducing bargaining inefficiency, even though behavior is somewhat affected by awareness of the screening process. ${ }^{26}$

The significant increase in dictator allocations observed in this treatment is evidence that subjects believed that there was some value in being in the $\mathrm{H}$ group for bargaining. This establishes that people do take into account information about "fairness" 
when choosing their actions. Since people allocated substantially more to attempt to qualify for the $\mathrm{H}$ group, this suggests potential effectiveness for a mechanism whereby people must pay a sum to give a "good-faith" signal of their willingness to be cooperative in attempting to resolve a dispute.

Optimal Strategy. The reversal of the earnings differential for $\mathrm{H}$ and $\mathrm{L}$ types from Treatment 1 to Treatment 2 leads to the issue of optimal bargaining behavior for a purely strategic player, who knows the results of these sessions. If we assume that this player is able to choose a label (in Treatment 1) and to mimic the bargaining behavior of either type, we can determine conditional expected profits. ${ }^{27}$ These are shown in the graphs in Appendix J. In the 1st study, these conditional earnings are:

$$
\begin{array}{rlrl}
\Pi^{\mathrm{e}}(\mathrm{H} \mid \mathrm{L}) & =249.5 & \Pi^{\mathrm{e}}(\mathrm{H} \mid \mathrm{H})=286.8 \\
\Pi^{\mathrm{e}}(\mathrm{L} \mid \mathrm{L})=261.6 & \Pi^{\mathrm{e}}(\mathrm{L} \mid \mathrm{H})=252.7
\end{array}
$$

Here, $\Pi^{\mathrm{e}}(\mathrm{T} \mid \mathrm{t})$ is the expected profit for a "T" type if paired with a " $\mathrm{t}$ " type. We have $\Pi^{\mathrm{e}}(\mathrm{H})=286.8 \mathrm{q}+249.5(1-\mathrm{q})$ and $\Pi^{\mathrm{e}}(\mathrm{L})=252.7 \mathrm{q}+261.6(1-\mathrm{q})$, where $\mathrm{q}$ represents the likelihood of being matched with a high type, so that an $\mathrm{H}$ type has higher expected earnings iff $\mathrm{q}>.26$. Recall that $\mathrm{q}=.44$ in Treatment 1.

The results for the 2nd study are quite different. Expected conditional earnings are:

$$
\begin{array}{ll}
\Pi^{\mathrm{e}}(\mathrm{H} \mid \mathrm{L})=237.3 & \Pi^{\mathrm{e}}(\mathrm{H} \mid \mathrm{H})=272.4 \\
\Pi^{\mathrm{e}}(\mathrm{L} \mid \mathrm{L})=271.8 & \Pi^{\mathrm{e}}(\mathrm{L} \mid \mathrm{H})=291.9
\end{array}
$$

\footnotetext{
26 The gender result is another indication that bargaining behavior and consequent inefficiency can vary across types. There may be different norms of appropriate social interaction for each gender.

27 These are based on average earnings derived from settlement values less average dispute costs for each pairing-type. The average result for two people in a like-type pair is obviously 300 less the dispute cost. The expected cross-pair earnings are calculated from Appendix G.
} 
Thus, $\Pi^{\mathrm{e}}(\mathrm{H})=272.4 \mathrm{q}+237.3(1-\mathrm{q})$, and $\Pi^{\mathrm{e}}(\mathrm{L})=291.9 \mathrm{q}+271.8(1-\mathrm{q})$. In this case $\mathrm{L}$ types have higher expected earnings for all feasible values of $\mathrm{q}$. This is a strong contrast to the indicated strategy in Treatment 1 . Without identification, one is best advised to obey the strategic imperative of non-cooperation and adversarial behavior. However, if a credible screening mechanism for screening and identification is available, a more cooperative approach is indicated with even only a sizable minority of $\mathrm{H}$ types in the population.

\section{CONCLUSION}

In this experiment, bargaining efficiency is enhanced by screening and identifying the participants. The dictator game functions as one such screen here; doubtless, there are other, and better, devices. Benefits are particularly large when two high types are paired and when they are aware of this pairing. In the context of the Rabin model, information about fairness has significant consequences; for example, the dispute cost for $\mathrm{HH}$ pairs doubles when they are not told about types. This information is critical, as differences across types of pairs are otherwise greatly diminished and sorting loses its effectiveness. There is also some evidence that there are reciprocal altruists present, since, if $\mathrm{H}$ types were pure altruists, we would expect dispute costs for LL pairs to be higher than for mixed pairs. While this cannot be rejected at statistically significant levels, mixed pairs do in fact have the highest dispute cost in all cases. One's disposition toward another may depend on exogenous information, as well as specific action choices in a game. 
In keeping with Roth and Malouf (1979) and Roth and Schoumaker (1983), this information appears to lead to the formation of exogenous expectations, which significantly affect outcomes. Exogenous expectations, based on information about chosen dictator game allocations, have serious effects on outcomes, since beliefs about others is found to affect bargaining behavior. The highly significant difference in dictator game allocations across treatments is also evidence that people consider information about fairness quite relevant. In this case, information about historical generosity can lead subjects to believe that norms are shared, reducing coordination problems and allowing a more efficient bargaining process.

The reversal of the earnings differential for $\mathrm{H}$ and $\mathrm{L}$ types is an important result, as it suggests that the "strategic imperative" of aggressive behavior may be reduced or eliminated under some circumstances. The information provided by identification is key for theoretical optimal strategic behavior, since optimal strategies are quite different in the corresponding treatments. This could have significant implications for the design of dispute resolution mechanisms.

In the dispute resolution literature, there have been proposals for determining the appropriate dispute resolution approach on the basis of the nature of the dispute. ${ }^{28}$ However, such matching schemes do not consider the relationship of the parties or their "types." It is quite possible that the effectiveness of any matching process in improving bargaining efficiency in disputes can be substantially enhanced with a screening process.

\footnotetext{
${ }^{28}$ For example, Sander and Goldberg (1994) discuss criteria for matching methods with types of disputes. See also Ury, Brett, and Goldberg (1988). In fact, the Multi-Door Courthouse project in Washington, D.C. is an actual attempt to match features of a case with one of several court-annexed procedures.
} 


\section{REFERENCES}

Albin, Cecilia, "The Role of Fairness in Negotiation," Negotiation Journal, 1993, Vol. 9, p. $223-236$

Ashenfelter, Orley, Janet Currie, Henry Farber, and Matthew Spiegel, "An Experimental Comparison of Dispute Rates in Alternative Arbitration Systems," Econometrica, 1992, Vol. 60, pp. 1407-1433

Axelrod, Robert, The Evolution of Cooperation, 1984

Axelrod, Robert and William Hamilton, "The Evolution of Cooperation," Science, Vol. 211, 1981, pp. 1390-6

Bolton, Gary, "Dispute Costs versus Award Symmetry: An Arbitration Experiment," Unpublished manuscript, Penn State University, January, 1995

Chatterjee, Kaylan and William Samuelson, "Bargaining under Incomplete Information," Operations Research, 1983, Vol. 31, pp. 835-851

Cooper, Russell, Douglas DeJong, Robert Forsythe, and Thomas Ross, "Communication in Coordination Games," 1992, Quarterly Journal of Economics, Vol. 107, pp. 739-771

Croson, Rachel, "Information in Ultimatum Games: An Experimental Study," manuscript, 1993, Harvard University

Dawes, Robyn, Jeanne McTavish, and Harriet Shaklee, "Behavior, Communication and Assumptions about Other People's Behavior in a Commons Dilemma Situation," Journal of Personality and Social Psychology, 1977, Vol. 35, pp. 1-11 
Epps, T. W. and K. Singleton, "An Omnibus Test for the Two Sample Problem Using the Empirical Characteristic Function," Journal of Statistical Computation and Simulation, 1986, Vol. 26, pp. 177-203

Forsythe, Robert, Joel Horowitz, N. Savin, and Martin Sefton, "Fairness in Simple Bargaining Experiments," Games and Economic Behavior, 1994, Vol. 6, pp. 347-369

Frank, Robert H., Passions within Reason: The Strategic Role of the Emotions, 1988 Fudenberg, Drew and Jean Tirole, "Sequential Bargaining with Incomplete Information," Review of Economic Studies, 1983, Vol. 50, pp. 221-247

Guth, Werner and Reinhard Tietz, "Ultimatum Bargaining Behavior: A Survey and Comparison of Results," Journal of Experimental Psychology, 1990, Vol. 11, pp. 417-449

Harsanyi, John and Reinhard Selten, A General Theory of Equilibrium Selection, 1988

Hoffman, Elizabeth, Kevin McCabe, and Vernon Smith, "Social Distance and OtherRegarding Behavior in Dictator Games," Unpublished manuscript, Economic Science Laboratory, University of Arizona, October, 1994

Kelley, Harold and Anthony Stahelski, "Errors in Perception of Intentions in a MixedMotive Game," Journal of Experimental Social Psychology, 1970, Vol. 6, pp. 379-400

Rabin, Matthew, "Incorporating Fairness into Game Theory and Economics," American Economic Review, 1993, Vol. 83, pp. 1281-1302

Roth, Alvin, "Bargaining Experiments," in Handbook of Experimental Economics, John Kagel and Alvin Roth, eds., 1995 
Roth, Alvin, "Toward a Focal-Point Theory of Bargaining," in Game-Theoretic Models of Bargaining, 1985, Alvin Roth, ed.

Roth, Alvin and Michael Malouf, "Game-Theoretic Models and the Role of Information in Bargaining: An Experimental Study," Psychological Review, 1979, Vol. 86, pp. 574-594

Roth, Alvin and Francoise Schoumaker, "Expectations and Reputations in Bargaining: An Experimental Study," American Economic Review, 1983, Vol. 73, pp. 362-372

Sander, Frank and Stephen Goldberg, "Fitting the Forum to the Fuss: A User-Friendly Guide to Selecting an ADR Procedure," Negotiation Journal, 1994, Vol. 10, pp. 49-68

Siegel, Sidney and N. John Castellan, Non-Parametric Statistics for the Behavioral Sciences, 1988

Ury, William, Jeanne Brett, and Stephen Goldberg, Getting Disputes Resolved, 1988

\section{APPENDIX A -DICTATOR GAME INSTRUCTIONS (TREATMENT 1 AND TREATMENT 2)}

\section{INSTRUCTIONS}

You have been asked to participate in an economics experiment. For your participation today we will pay you $\$ 5$ in cash at the end of the experiment. You may also earn an additional amount of money, which will also be paid to you in cash at the end of the experiment.

In this experiment each of you will be paired with a different person who is not in this room. You will not be told who these people are either during or after the experiment, and they will not be told who you are either during or after the experiment.

You will notice that there are other people in the same room with you who are participating in the experiment. They will also be paired with different people who are not in this room. Your decision and their decisions are completely independent.

The experiment is conducted as follows: A sum of $\$ 5$ has been provisionally allocated to each pair and the person in Room A can propose how much of this each 
person is to receive. To do this, the person in Room A must fill out a form titled "Proposal Form." If you are in Room A, you will find two copies of this form on the desk in front of you. The first line of this form tells you your identification number. The identification number of the person you are paired with is on line (2). The amount to be divided is on line (3).

The person in Room A makes the proposal. The proposal consists of an amount the person in Room B is to receive (entered on line (4) ) and the amount the person in Room A is to receive (entered on line (5) ). The amount the person in Room A is to receive is simply the total amount to be divided, $\$ 5$, minus the amount the person in Room $\mathrm{B}$ is to receive. An illustrative chart has been provided on the proposal form.

If you are in Room A you will have five minutes to come to a decision about your proposal. At the end of five minutes, a buzzer will sound. Do not talk to the other people in your room until your session is completed. Do not be concerned if other people make their decisions before you, we will not collect the forms until the buzzer sounds.

You should record the same amounts on the other copy of your proposal form. One copy is for your records and the other copy will be sent to the person in Room B with whom you are paired.

After the buzzer sounds, the proposal forms will be collected. Each person will receive $\$ 5$ for participating. Each person in Room A will also receive the amount shown on line (5) of his or her proposal form. Each person in Room B will also receive the amount shown on line (40 of the form.

Thank you for your participation. Are there any questions? 


\section{APPENDIX B - PROPOSAL FORM}

\section{PROPOSAL FORM}
(1) Identification number
A
(2) Paired with
B
(3) Amount to divide
$\$ 5.00$
(4) Person in Room B receives
(5) Person in Room A receives (3) - (4)

Person in Room B receives:

Person in Room A receives:

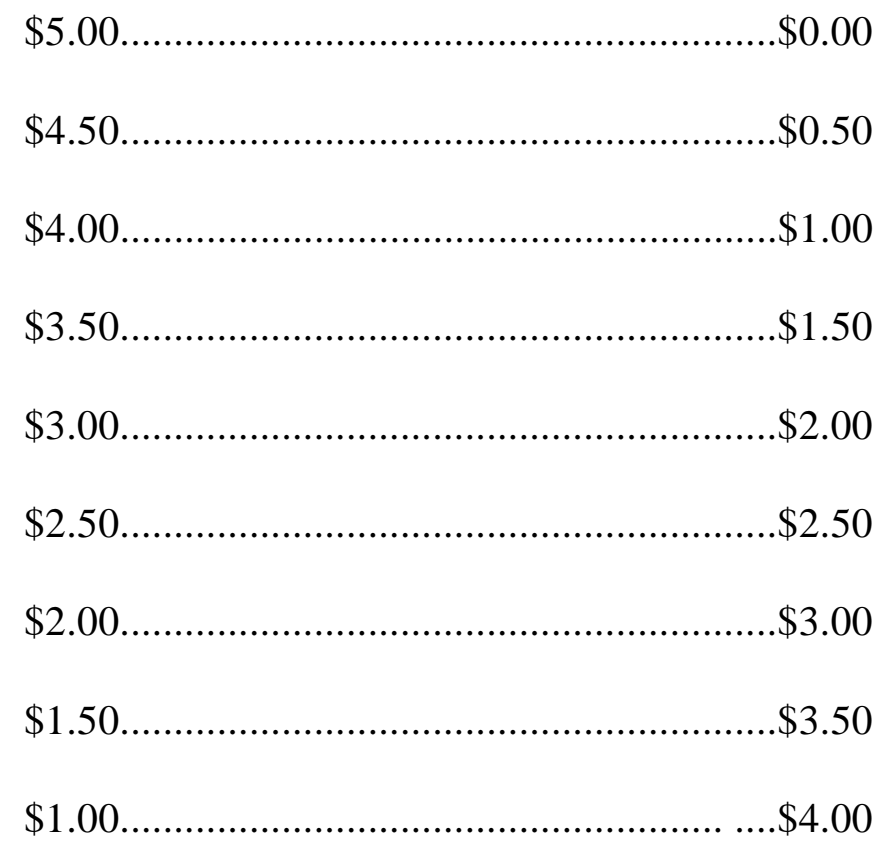




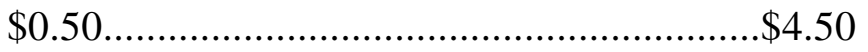

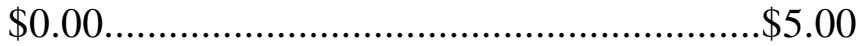




\section{APPENDIX C - BARGAINING INSTRUCTIONS}

\section{SUPPLEMENTAL INSTRUCTIONS}

You have been given 600 seconds to reach an agreement. After each 100 seconds of elapsed time, both your payoffs and the other person's payoffs will be reduced by $4 \%$. Thus, for example, if you reach agreement with 486 seconds remaining in the bargaining session, the payoffs would be reduced by $4 \%$. If your Payoff Schedule shows a payoff of 300 for the number agreed upon, this would be reduced by $4 \%$ to 288 . Similarly, if you reach agreement with 374 seconds remaining in the session, all payoffs would be reduced by $8 \%$. If your Payoff Schedule shows a payoff of 300 Plato dollars, this would be reduced by $8 \%$ to 276 . If you reach agreement with 509 seconds remaining, there would be no reduction in the payoffs, since less than 100 seconds have elapsed. If agreement is reached with 25 seconds remaining in the session, payoffs would be reduced by $20 \%$. If you do not reach agreement in the time allotted for bargaining, a resolution will be made through arbitration. A ruling will be made and this ruling will determine your payoff. There is an additional cost of $20 \%$ of the original payoff if arbitration is required. Thus, if arbitration is invoked, all payoffs would be reduced by a total of $40 \%$ - the $20 \%$ reduction from the first 500 seconds of elapsed time plus the additional $20 \%$ reduction for arbitration. These reductions are intended to simulate the cost of extended bargaining and/or arbitration. So, for example, if the number determined by arbitration would yield a payoff of 300 Plato dollars from your original payoff schedule, this number would only give a payoff of 180 Plato dollars. Remember these reduction rules as you bargain.

Again, if you go to arbitration, whatever number selected through arbitration will determine your payoffs. Your actions prior to arbitration will not affect the arbitration process: negotiations and arbitration are completely separate.

You are being given a sheet with the past 100 arbitrator decisions. This sheet may be used to give you some idea of what to expect of an arbitration ruling. 
The Payoff Schedule for the person with whom you are paired is reversed from yours. If your payoffs increase with increasing offers, the other person's payoffs decrease with increasing offers, and vice versa. 


\section{APPENDIX D -DICTATOR INSTRUCTIONS}

(TREATMENT 3)

\section{INSTRUCTIONS}

You have been asked to participate in an economics experiment. For your participation today we will pay you $\$ 5$ in cash at the end of the experiment. You may also earn an additional amount of money, which will also be paid to you in cash at the end of the experiment.

In this experiment each of you will be paired with a different person who is not in this room. You will not be told who these people are either during or after the experiment, and they will not be told who you are either during or after the experiment.

You will notice that there are other people in the same room with you who are participating in the experiment. They will also be paired with different people who are not in this room. Your decision and their decisions are completely independent.

The experiment is conducted as follows: A sum of $\$ 5$ has been provisionally allocated to each pair and the person in Room A can propose how much of this each person is to receive. To do this, the person in Room A must fill out a form titled "Proposal Form." If you are in Room A, you will find two copies of this form on the desk in front of you. The first line of this form tells you your identification number. The identification number of the person you are paired with is on line (2). The amount to be divided is on line (3).

The person in Room A makes the proposal. The proposal consists of an amount the person in Room B is to receive (entered on line (4) ) and the amount the person in Room A is to receive (entered on line (5) ). The amount the person in Room A is to receive is simply the total amount to be divided, $\$ 5$, minus the amount the person in Room $\mathrm{B}$ is to receive. An illustrative chart has been provided on the proposal form.

In addition, your proposal will affect your subsequent pairing in the bargaining game you have just experienced. People in the half of the group that allocates the highest amounts to others will be paired with each other. Those who allocate the lesser amounts to others will also be paired with each other. There will be 2 rounds of the bargaining game played; each round will be a new pairing. You will be informed which half of the group you are in.

If you are in Room A you will have five minutes to come to a decision about your proposal. Do not talk to the other people in your room until your session is completed. Do not be concerned if other people make their decisions before you, we will not collect the forms until time is up.

You should record the same amounts on the other copy of your proposal form. One copy is for your records and the other copy will be sent to the person in Room B with whom you are paired.

When time is up, the proposal forms will be collected. Each person will receive $\$ 5$ for participating. Each person in Room A will also receive the amount shown on line (5) 
of his or her proposal form. Each person in Room B will also receive the amount shown on line (4) of the form.

Thank you for your participation. Are there any questions? 


\section{APPENDIX E - SAMPLE OF PAST DECISIONS}

Arbitrator's Past 100 Decisions

$\begin{array}{llllllllll}334 & 287 & 280 & 259 & 343 & 164 & 414 & 197 & 264 & 353 \\ 377 & 278 & 223 & 296 & 230 & 280 & 373 & 270 & 320 & 333 \\ 345 & 207 & 229 & 247 & 270 & 296 & 297 & 174 & 320 & 291 \\ 269 & 324 & 341 & 306 & 345 & 276 & 211 & 313 & 268 & 335 \\ 349 & 337 & 314 & 222 & 284 & 311 & 207 & 283 & 219 & 290 \\ 310 & 291 & 390 & 232 & 375 & 288 & 234 & 323 & 336 & 335 \\ 319 & 336 & 387 & 368 & 270 & 279 & 369 & 263 & 325 & 281 \\ 359 & 261 & 229 & 340 & 345 & 303 & 328 & 326 & 214 & 240 \\ 290 & 276 & 218 & 401 & 315 & 153 & 315 & 310 & 307 & 278 \\ 292 & 355 & 316 & 332 & 393 & 279 & 256 & 296 & 272 & 373\end{array}$




\section{APPENDIX F}

DATA SUMMARY

DISPUTE COSTS BY PAIR-TYPE

Treatment 1 (Identified sorting)

Pair-type \# of sessions with \%cost:

\begin{tabular}{lllllll}
0 & 4 & 8 & 12 & 16 & 20 & 40 \\
\hline
\end{tabular}

Avg. dispute cost

$\mathrm{HH}$

LL

$\begin{array}{lllllll}13 & 10 & 1 & 2 & 1 & 0 & 1\end{array}$

$4.6 \%$

$\begin{array}{lllllll}7 & 12 & 6 & 5 & 1 & 1 & 8\end{array}$

$12.8 \%$

CROSS

$\begin{array}{lllllll}7 & 2 & 3 & 2 & 3 & 2 & 7\end{array}$

$16.3 \%$

UNSORTED

$\begin{array}{lllllll}6 & 3 & 7 & 4 & 3 & 3 & 4\end{array}$

$12.8 \%$

Treatment 2 (No identification)

Pair-type \# of sessions with \%cost:

\begin{tabular}{lllllll}
0 & 4 & 8 & 12 & 16 & 20 & 40 \\
\hline
\end{tabular}

$\underline{\text { Avg. dispute cost }}$

$\mathrm{HH}$

$\begin{array}{lllllll}4 & 10 & 8 & 1 & 3 & 1 & 2\end{array}$

$9.2 \%$

LL

$\begin{array}{lllllll}5 & 11 & 4 & 3 & 2 & 3 & 3\end{array}$

$9.4 \%$

CROSS

$\begin{array}{lllllll}10 & 8 & 4 & 1 & 2 & 2 & 6\end{array}$

$11.8 \%$

Treatment 3 (Bidding, then sorting)

Pair-type \# of sessions with \%cost:

\begin{tabular}{lllllll}
0 & 4 & 8 & 12 & 16 & 20 & 40 \\
\hline
\end{tabular}

$\underline{\text { Avg. dispute cost }}$

$\mathrm{HH}$

$\begin{array}{rrrrrrr}7 & 8 & 6 & 6 & 4 & 2 & 1 \\ 5 & 10 & 3 & 4 & 3 & 4 & 5\end{array}$

$8.7 \%$

LL

$\begin{array}{lllllll}5 & 10 & 3 & 4 & 3 & 4 & 5\end{array}$

$12.9 \%$ 


\section{APPENDIX G}

\section{CROSS-PAIR OUTCOMES ${ }^{291}$ (TREATMENT 1)}

$\begin{array}{rcc}\text { Pair } & \text { Settlement } & \text { Dispute cost }(\%)^{302} \\ 1 & 160 & 8 \\ 2 & 300 & 16 \\ 3 & 324 & 40 \\ 4 & 240 & 0 \\ 5 & 200 & 16 \\ 6 & 290 & 20 \\ 7 & 309 & 40 \\ 8 & 318 & 40 \\ 9 & 360 & 20 \\ 10 & 300 & 0 \\ 11 & 390 & 8 \\ 12 & 278 & 40 \\ 13 & 290 & 0 \\ 14 & 370 & 8 \\ 15 & 302 & 0 \\ 16 & 350 & 4 \\ 17 & 245 & 0 \\ 18 & 319 & 40 \\ 19 & 288 & 40 \\ 20 & 260 & 12 \\ 21 & 250 & 4 \\ 22 & 325 & 0 \\ 23 & 260 & 16 \\ 24 & 400 & 0 \\ 25 & 316 & 40 \\ 26 & 364 & 12 \\ & & \\ \text { Average } & 300.4 & 16.3\end{array}$

Summary: The average is slightly above 300, indicating that the average payoff for the high type was greater than for the low type. There were 19 non-arbitrated cases, with $\Pi_{L}$ $>\Pi_{H}$ in 8 cases, $\Pi_{L}<\Pi_{H}$ in 9 cases, and 2 ties. Excluding the 7 arbitrated cases from the sample, the average settlement number is 298.1 .

\footnotetext{
${ }^{291}$ Recall that the bargaining range was from 100 to 500. I have organized the actual ordering in the pairings so that the high type receives higher payoffs as the settlement number increases. The two subjects in a pair would receive equal payoffs when there is a settlement at 300. Settlement at a number higher than 300 indicates that the high type received a payoff greater than that of the paired low type.

$3^{30}$ A dispute cost of 40 indicates that arbitration was required.
} 



\section{APPENDIX H}

\section{CROSS-PAIR OUTCOMES ${ }^{311}$ (TREATMENT 2)}

\begin{tabular}{|c|c|c|}
\hline Pair & Settlement & Dispute $\operatorname{cost}(\%)^{322}$ \\
\hline 1 & 250 & 4 \\
\hline 2 & 218 & 40 \\
\hline 3 & 356 & 40 \\
\hline 4 & 303 & 0 \\
\hline 5 & 100 & 12 \\
\hline 6 & 265 & 8 \\
\hline 7 & 325 & 0 \\
\hline 8 & 300 & 0 \\
\hline 9 & 281 & 4 \\
\hline 10 & 269 & 20 \\
\hline 11 & 268 & 4 \\
\hline 12 & 300 & 0 \\
\hline 13 & 400 & 0 \\
\hline 14 & 173 & 20 \\
\hline 15 & 376 & 40 \\
\hline 16 & 259 & 0 \\
\hline 17 & 280 & 40 \\
\hline 18 & 200 & 4 \\
\hline 19 & 265 & 40 \\
\hline 20 & 310 & 4 \\
\hline 21 & 283 & 0 \\
\hline 22 & 277 & 4 \\
\hline 23 & 232 & 40 \\
\hline 24 & 290 & 8 \\
\hline 25 & 393 & 8 \\
\hline 26 & 278 & 0 \\
\hline 27 & 188 & 16 \\
\hline 28 & 300 & 4 \\
\hline 29 & 275 & 16 \\
\hline 30 & 175 & 4 \\
\hline 31 & 200 & 8 \\
\hline 32 & 350 & 0 \\
\hline 33 & 251 & 0 \\
\hline Average & 272.4 & 11.8 \\
\hline
\end{tabular}

$31^{1}$ I have organized the actual ordering in the pairings so that the high type receives higher payoffs as the settlement number increases. The two subjects in a pair would receive equal payoffs when there is a settlement at 300 . Settlement at a number higher than 300 indicates that the high type received a payoff greater than that of the paired low type.

$32^{2}$ A dispute cost of 40 indicates that arbitration was required. 
Summary: The average is far below 300, indicating that the average payoff for the low type was greater than for the high type. There were 27 non-arbitrated cases, with $\Pi_{L}>$ $\Pi_{H}$ in 18 cases, $\Pi_{L}<\Pi_{H}$ in 6 cases, and 3 ties. Excluding the 6 arbitrated cases from the sample, the average settlement number is 269.0 . 


\section{APPENDIX I}

\section{GENDER RESULTS}

In Treatment 3, there was one session where all 8 participants were female and one session when all 8 participants were male. The data from these is shown below:

$\underline{\text { Gender }}$

\# of sessions with \%cost:

$\underline{\text { Avg. dispute cost }}$

\begin{tabular}{lllllll}
0 & 4 & 8 & 12 & 16 & 20 & 40 \\
\hline
\end{tabular}

Female

$\begin{array}{lllllll}3 & 3 & 2 & 3 & 1 & 0 & 0\end{array}$

$6.7 \%$

Male

$\begin{array}{lllllll}1 & 1 & 1 & 1 & 3 & 4 & 1\end{array}$

$16.0 \%$ 


\section{APPENDIX J}

FITTED EARNINGS EXPECTATIONS FOR HIGH AND LOW TYPES (Treatment 1)

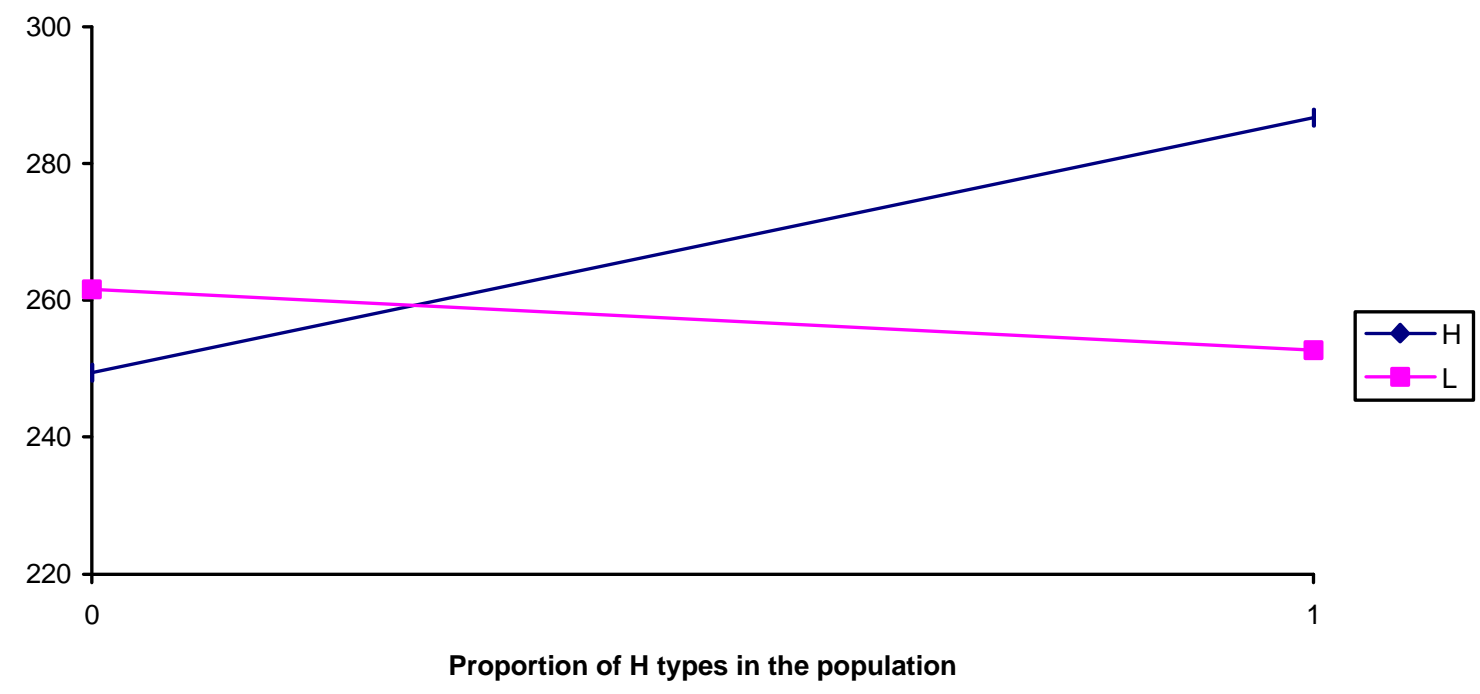

FITTED EARNINGS EXPECTATIONS FOR HIGH AND LOW TYPES (Treatment 2)

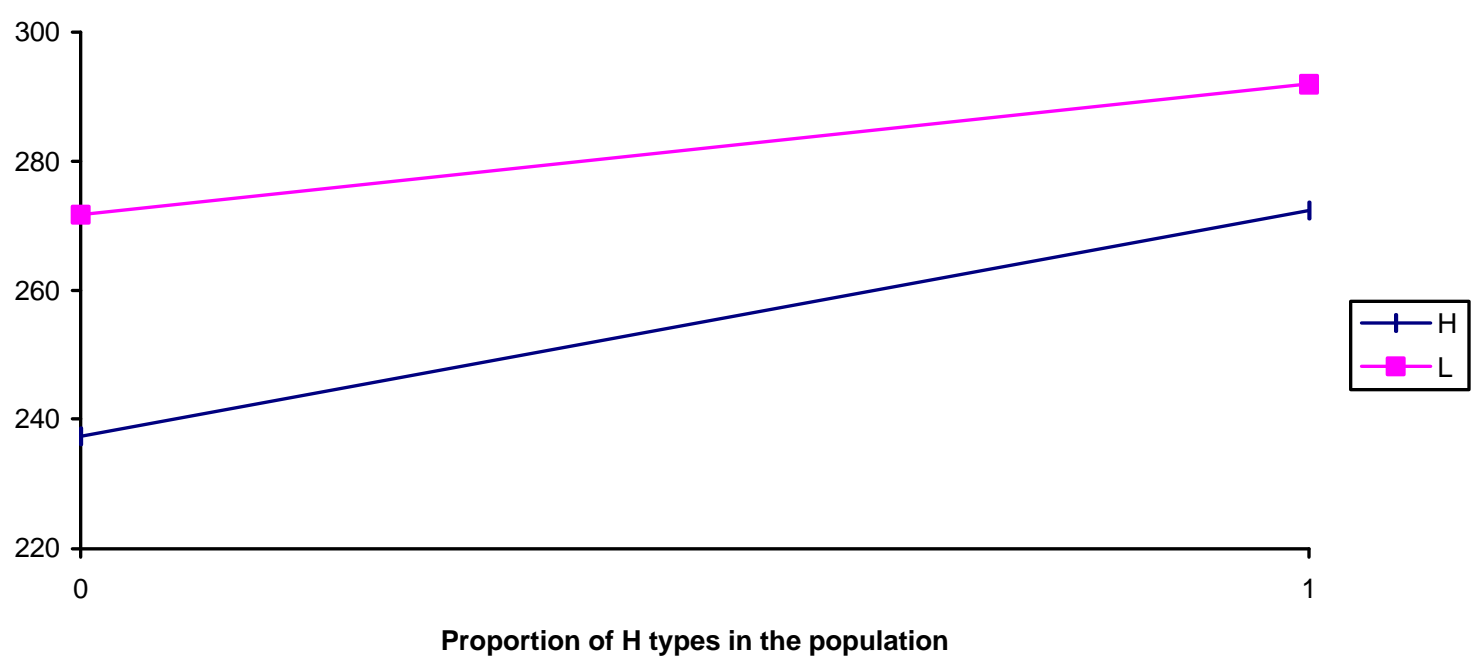


